\title{
Beyond Poverty
}

\author{
Jonathan Wolff
}

\begin{abstract}
Poverty is often defined as lacking the financial resources to meet a defined set of needs. The stated level of financial resources is taken to define a poverty line. Accordingly, the clear policy response to poverty is to raise the incomes of those who fall below such a line. In this paper, drawing on the capability approach, I argue that this approach is limited in two related ways, and it is necessary to move "beyond poverty" both in a conceptual and a policy sense. First, it is rarely if ever the case that a particular level of financial resources is necessary or sufficient to meet a set of needs, as other factors also act as critical inputs. Second, to bring people over the threshold set of needs, policies that do not raise income, such as the provision of collective goods, will often be more effective in the long term than income transfers. Nevertheless, in the short-term raising incomes will often be the easiest and most available strategy and hence there is also reason to retain the concept of poverty and related policies.
\end{abstract}

Keywords Poverty $\cdot$ Rowntree $\cdot$ Poverty line $\cdot$ Capabilities approach $\cdot$ Deprivation - Disadvantage

[W]orking people are just as human as those with more money. They cannot live just on a 'fodder basis'. They crave for relaxation and recreation just as the rest of us do. But ... they can only get these things by going short of something which is essential to physical fitness, and so they go short .... They pay dearly for their pleasures! (Rowntree 1937, pp. 126-127).

J. Wolff $(\bowtie)$

Oxford University, Oxford, UK

e-mail: jonathan.wolff@bsg.ox.ac.uk 


\section{Introduction}

In 1901 Benjamin Seebohm Rowntree published his famous study of poverty in York (Rowntree 1901). Aimed at a sceptical audience, some of whom, it is said, believed that as there was virtually no unemployment in York at the time there could be no poverty, Rowntree set out to show that very many workers in York were unable to afford a decent human life on the income they received. Calculating what was required to achieve what he then called "physical efficiency" - a minimum standard of nutrition, housing and clothing-Rowntree showed that a substantial number of families in York were not able to achieve this level. They were, he said, in "primary poverty", showing "obvious want and squalor".

Rowntree also pointed out that another substantial proportion of the workers of York lived in obvious want and squalor, despite having the financial resources to avoid doing so. They spent at least some of their money in ways that did not advance their physical efficiency, and therefore they failed to achieve it. One explanation is that many may have lacked the budgeting and food preparation skills to convert income into physical efficiency as effectively as they might have done. But equally some people were simply choosing to spend some of their money on other things: on alcohol, on entertainment, on birthday presents, or even on stationery and stamps to correspond with family members living away from York. What he called the primary poverty line was deliberately, and unrealistically, austere. This was, at least in part, because it was adopted for a political purpose; to respond to the conservatives mentioned above who denied there was poverty in York. The lower the poverty line, the more compelling Rowntree's case, if substantial numbers are found below it. ${ }^{1}$ But Rowntree clearly also had a great deal of sympathy for people living in what he termed secondary poverty. He wrote, with sensitive understanding, for example, of why young people chose to spend their evenings, and part of their meagre wages, in pubs (Rowntree 1901, pp. 311-312), even though Rowntree himself was a member of the temperance movement and opposed the drinking of alcohol.

Rowntree was a pioneer in the study of poverty. There is, therefore, something slightly uncomfortable in using Rowntree's writings as the starting point of this paper, which aims, in part, to draw out a central instability in the concept of poverty. The general issue has been brought out very well in Sen's writings (for example Sen 1980, 1983, 1999). Poverty is generally defined as lacking the financial resources necessary and sufficient to achieve a set of particular goals, normally connected with what is needed to stay alive in good health. But, in fact, it is rarely, if ever, the case that financial resources are strictly necessary in order to achieve those goals. For example, making a range of goods free at the point of consumption could be enough to ensure physical efficiency for all, even for people on no income at all. This observation leads to two related points. First, more work needs to be done to explain why lack of financial resources is picked out as an especially important cause of failing to achieve particular goals. Second, and critically for social policy,

${ }^{1}$ For an insightful discussion see Viet-Wilson (1986). 
a concentration on poverty defined in terms of inadequate income encourages a focus on income-based social policies, whereas in some cases the provision of public goods, or forms of social change, could be alternative solutions, often with significant advantages (see Wolff 2018).

Poverty researchers are well-aware of these problems, and, for example, will sometimes work out ways of including "in-kind" goods in poverty calculations, perhaps by converting them into income-equivalent sums. Also, for this reason, some philosophers prefer to talk about deprivation rather than poverty (Hull 2007), or, in my own work, disadvantage (Wolff and de-Shalit 2007). However, while there is analytic clarity in moving to a more general framework in which lack of financial resources is one factor in a complex matrix of causes of a failure to meet needs, there is no doubt that the concept of poverty has a strong political resonance and urgency. To abandon the concept would also cut us adrift from more than a century of research and data collection. There are, therefore, reasons to retain the concept (Lister 2004; Wolff et al. 2015). But at the same time, it is important to recognize its limitations. My broad, and bland, claim is that different concepts will be appropriate for use in different circumstances, and hence it is wrong to insist on a single concept, definition, or measure to be used in all cases. Different notions of poverty or deprivation or disadvantage will be needed for different purposes. My somewhat more adventurous claim is that the more fixed the background social structures are, the more helpful the concept of poverty will be, as it is very often easier to change incomes than anything else, especially in the short term. Given that change in structure takes time, the natural conclusion is that the concept of poverty, understood in financial terms, will be very useful in thinking through short term social objectives, but less so in longer term planning.

\section{The Poverty Line}

To use the concept of poverty requires a statement of a poverty line. As we have seen, the general conception of poverty is to lack the financial resources needed to achieve particular goals, understood as a bundle of goods or services. Rowntree wanted to define the primary poverty line in financial terms so that it is possible to determine how many people in a given area fail to meet it. As we saw in 1901, he defined the appropriate bundle of goods or services in narrow terms. By 1937 Rowntree abandoned the distinction between primary and secondary poverty. Rather, he included a modest additional sum for "sundries", which might include tobacco, alcohol, going to a football match, a daily newspaper, a wireless, and holidays. For this he allowed what he referred to as "little more than the cost of a cocktail" (Rowntree 1937, p. 12). At first it may seem incongruous that Rowntree mentions a cocktail in relation to a working family's need for entertainment, but it is likely that Rowntree takes himself to be writing for a well-to-do audience. In setting out the requirements of a minimally decent life Rowntree is aware that some of his readers will suspect that he is being sentimentally indulgent and is setting the 
line at the level of extravagance rather than at a properly minimal standard. Hence, he compares the tight money management of those on low incomes with the careless spending of the rich. At another point in the book he contrasts the recommended daily calorie intake for a man undertaking physical work (3400) with the actual intake of a gentleman staying at a West End club (5148) (Rowntree 1937, p. 75).

Although it is not part of Rowntree's explicit agenda to make a moral case for poverty relief, these comparisons can be seen as an intervention in a moral argument. And it may be helpful to run through at least an outline of the most prominent strands in moral debates concerning poverty relief to provide a context for some of the arguments to follow.

One place to start is from the challenge, perhaps issued by a cocktail drinking member of a West End Club, "why should the plight of the poor be any concern of mine?" There is, naturally, something artificial about this question, as most moral and religious positions accept that the wealthy have at least some kind of moral duty to help at least some of the poor, at least in theory. Perhaps some forms of extreme libertarianism, or, more common in popular morality, social Darwinism, would deny that there are any duties of assistance. Indeed, the social Darwinist might argue that there is a duty not to intervene. Those who take the contrary view, and suppose that there is a moral duty to help, possibly take inspiration from the religious thought "there but for the grace of God go I", or in less poetic, philosophical, idiom, Rawls points out that such inequalities of fortune are "arbitrary from a moral point of view" (Rawls 1999, p. 72).

The root of this moral approach is the idea that all people share a common humanity, and are entitled to live a fully human life, yet poverty is in some sense dehumanizing (Jones 1990). Hennie Lötter makes the interesting observation that we tend only to apply the term "poverty" to human beings. An elephant can be starving, ill, or ill-treated, but we would never naturally say that it is living in poverty (Lötter 2011). And, indeed, poverty discourse is shot-through with animal/human imagery. In the opening quote, we saw Rowntree used the idea that the poor cannot live on a "fodder" - animal feed-basis. Robert Walker quotes comparisons of poor people with "fighting like dogs over every bone" (Walker 2014, p. 76) and being "dirty as pigs" (Walker 2014, p. 80). Poverty is seen as depriving men of their manhood and mothers of their maternal pride (Walker 2014, p. 185). In one unusual image, even those on welfare benefits are compared to a dolphin fed fish by a keeper (Walker 2014, p. 156).

The need to restore the humanity of those in poverty can, on the face of it, be used both to argue that individuals have a duty to make charitable donations and that the government needs to take steps to rearrange society so that poverty is eliminated. However, we need to be mindful of the "dolphin" analogy. While providing charitable assistance to those in poverty is certainly a moral improvement over not doing so, it will not always restore pride and humanity in those who are helped. Hence the elimination of poverty - the elimination of a need for help-appears to be a stronger priority than poverty relief. Now it is important not to overstate the point. It is not that being in need of help is dehumanizing, for I am sympathetic to a claim made by a range of philosophers, from Alasdair MacIntyre (1999) to Nell 
Noddings (1984) and others that being in need is part of human condition. But to receive help in a one-sided fashion can be experienced as humiliating and dehumanizing, especially if, had social conditions been different, it would not have been necessary, or at least not in that form. Hence, I will concentrate here on the political importance of removing poverty, rather than the charitable injunction to relieve it.

As I have noted it is, of course, possible that our cocktail drinking gentleman would refuse to accept either the philosophical or religious reason to take the plight of others seriously. But I think a much more common negative response would be to accept the argument in principle, but to deny that it applies to current circumstances. This would involve the counter-claim that the difference in the situations people find themselves in is not arbitrary from a moral point of view, or that it is not simply the grace of god that prevents me from finding myself in a similar situation.

There are many ways in which such counter-arguments can be set out. Here are some possibilities:

1. The particular people in question do not have the moral standing that entitles them to our concern. Perhaps they are immigrants, members of a despised religion or ethnic group, or followers of a debased life-style.

2. At least some poor people are poor through their own choice or negligence and do not deserve help.

3. There are limits to what the country can afford.

4. The moral duty to help is strictly constrained to meeting bare needs and the people in question already achieve this standard.

5. Help is self-defeating and will not improve the position of the poor.

People may be reticent to give the first of these arguments full voice in public debate, but a belief in it may instead provide a motivation for an individual to reach for one of the other arguments in respect to the group in question, and thereby sanitize their position by bringing it within the scope of public reason in a liberal regime. But in any case, each of these arguments comes in many forms, and there are many responses and counters. Rowntree was a Quaker and it is likely he is addressing an audience that, he assumes, will take their religious duties to help the poor seriously. However, he is very well aware that many have been tempted by some of the responses just outlined, and, most particularly, by the thought that the "moral" poverty line is lower than Rowntree paints it, and therefore what he is asking for goes beyond our moral duties.

As we can see from the quotation with which I started this paper, Rowntree was concerned that everyone should be able to lead a normal human life, with normal human activities, such as, in the example he uses himself, going to the cinema. Yet, he says, the poor "can only get these things by going short of something which is essential to physical fitness, and so they go short .... They pay dearly for their pleasures" (Rowntree 1937, pp. 126-127). This is, essentially, to reintroduce the concept of secondary poverty in all but name: the poor sacrifice their physical fitness to pursue other pleasures.

In doing this he anticipates the criticism that if the poor have enough to attain physical fitness then social duties are fulfilled, even if some people just above that 
level of income choose to spend at least some of their resources on other things. The argument he wishes for counter, then, combines the "constrained poverty line" argument (number 4 in the list above) with the "own fault" defence (number 2). Rowntree and his critics differ on whether having enough to stay alive in good health is the appropriate line, or whether there should be added the extra to turn an animal existence into a human one.

The critic's position of focusing only on physical fitness as the prime need is, on the face of it, a reasonably intuitive position, and, arguably, anticipates some elements of Maslow's "hierarchical theory of needs". In 1943 Maslow was to suggest that meeting physiological needs was human beings' prime motivation. After that, and in order, come needs for safety, love, esteem and self-actualization. "A person who is lacking food, safety, love, and esteem would most probably hunger for food more strongly than for anything else." (Maslow 1943, p. 373) He further illustrates his case with the remark:

The urge to write poetry, the desire to acquire an automobile, the interest in American history, the desire for a new pair of shoes are, in the extreme case, forgotten or become of secondary importance. For the man who is extremely and dangerously hungry, no other interests exist but food (Maslow 1943, pp. 373-374).

Although there is no necessity to use the theory in such a way it seems natural to say that this also sets out a moral hierarchy, in the sense of generating moral claims on others, with a grave urgency for food and shelter, and a cut-off point most likely after safety. There are well-known philosophical versions of such an idea, as, for example, Scanlon's paper "Preference and Urgency", which suggests that a person's need for food has a greater moral claim on others, even if the person with the claim would rather spend the money building a monument to his god (Scanlon 1975).

Yet Maslow himself warned against simplistic applications of his theory. First of all, he did not think that each more basic need had to be fully satisfied before people would be motivated to seek less basic ones. There is a level of reasonable satisfaction that allows attention to pass to the next level (Maslow 1943, p. 388). Furthermore, the theory is offered as a type of empirical generalization rather than a strict law. Hence Maslow accepts that for some people, and in some circumstances, hierarchy reversals happen. But it would, in any case, be mistaken to generalize an empirical theory of need into a moral theory of assistance, or at least not without some further assumptions. After all, as Maslow puts it, "Who is to say that a lack of love is less important than a lack of vitamins?" (Maslow 1943, p. 394).

What, then, do people seek at a high degree of priority beyond overcoming hunger and achieving safety? Rowntree would add entertainment, and also, at least by implication, rich social interaction inside and outside the family. Oddly, while Maslow talks about the painter and the composer of music who attempt to satisfy their self-actualisation needs, he does not mention leisure or the enjoyment of the creative arts of others. In their important work on financial diaries, in which people keep full records of all income and expenditure, Morduch and Schneider highlight the type of expenditure that throws people on fragile incomes off-course. In the United States, medical and car expenses are prominent, but of course these are 
direct and indirect contributions to physiological needs, especially when a car is needed in order to get to work (Morduch and Schneider 2017, pp. 51-52). Yet there are other items that also come up and seem to have a different role. Christmas expenses are mentioned several times (Morduch and Schneider 2017, pp. 12, 26, 52). Other items include wedding expenses, international travel home to see family (Morduch and Schneider 2017, p. 131), and home maintenance (Morduch and Schneider 2017, p. 115). Some people invest in their own and their children's future in the deliberate attempt to achieve upward mobility (Morduch and Schneider 2017, p. 49). Interestingly, severe financial strain is also caused by the felt need to match a new partner's spending habits (Morduch and Schneider 2017, p. 145) as well as taking in children of a friend who had died (Morduch and Schneider 2017, p. 146), and the need for a new computer for school work (Morduch and Schneider 2017, p. 146). In Morduch's earlier joint work, based on studies in India, Bangladesh and South Africa, medical, wedding, and funeral expenses were most likely to cause catastrophic disruption to orderly financial planning in highly straitened circumstances (Collins et al. 2009).

Examples can be multiplied, but the general picture is clear. In addition to wanting to meet physiological animal needs, many people put a high priority on what we can understand as their human needs. These will come in at least two forms: first, those that help secure a reasonable social and family life; and second, those that meet local social norms of respectable existence. Not throwing a proper wedding for your daughter, burying your father in a pauper's grave, or not being able to afford the right clothes for your children, will for many people be humiliating and a source of debilitating shame. This is the theme of relative poverty, which derives from observations by Adam Smith (Smith 1976 [1776]), and is developed by Peter Townsend (1979) and others. It is essentially the idea of not having enough to "fit in" by doing what is normally expected or encouraged (see also Wolff 2015b, 2017). The relation between poverty and shame is explored in detail by Robert Walker, who remarks that through shaming people in poverty, individuals and institutions socially construct poverty every day. (Walker 2014, p. 120). And for many people who do not find the courage to fight back, such shame can lead to withdrawal and isolation. As he says:

\footnotetext{
People in poverty are deemed by the majority to live 'on the wrong side of the track.' Avoided socially because they cannot afford to reciprocate, to stand a round of drinks, or to buy a suitable wedding present; employers fail to hire them, potential in-laws rebuff them, landlords refuse to house them, banks will not deal with them, moneylenders abuse them, officials lecture and coerce them, bailiffs evict them, and politicians chastise them (Walker 2014, p. 64).
}

We see, then, that what Rowntree described as secondary poverty can be not so much a type of dissolute extravagance that should rightly be condemned, as it often is in the popular press, but, in part at least, a type of psycho-social protection measure against shame. Few will know what you and your family are eating for dinner, but they will know whether you are dressed respectably and whether you meet norms of personal hygiene and grooming. As Narayan puts it, "the maintenance of cultural identity and social norms of solidarity helps poor people to continue to 
believe in their own humanity, despite inhuman conditions" (Narayan et al. 2000, pp. 4-5). And this has many resonances. For example, Ridge points out for young people wearing the right clothes is not simply a matter of shallow vanity, for it can often improve their confidence (Ridge 2002, p. 70). And, of course, how you dress and are groomed will affect your chances of getting a job or being taken seriously in a benefit interview, and so has a value beyond mere status. Going to a nail bar, or a barber, or a pub, or a betting shop is a way in which people on low income, struggling in many areas of life, can have their humanity reaffirmed, simply by being treated with the courtesy due to any paying customer. In sum, a poverty line needs to account for what it is to have a human life in the society in which one lives, even though this is far from a simple matter.

\section{Poverty and Capability}

In the opening section of this paper I mentioned an instability in the concept of poverty; essentially that poverty is defined in terms of a lack of the resources needed to achieve a certain set of goals related to human functioning, but that it is rarely true that resources are strictly necessary (or indeed sufficient) to achieve a set of functioning goals. Much of the discussion of the last section has focused on the failure to achieve particular goals, and it has implicitly been assumed that the absence or presence of money is the critical factor. In a broader context, however, we can see that there are other possible causes or cures. To see this, it will be helpful to build a schematic picture of poverty and deprivation, starting from Sen's helpful understanding of the capability approach (Sen 1980).

We need to begin with the distinction between capability and functioning. A functioning is a type of achievement—a being or doing — whereas a capability is, at its most basic, the opportunity to achieve that functioning. In a simplified model let us start with just two rudimentary, short-term, functionings: having a bed for the night, and having a nutritious meal. Although having the capability for both is likely to lead to enjoying both functionings, it is possible to have the capability for both of these but choose not to achieve either of them. For example, in order to lose weight and get exercise a wealthy person might decide to go on a night hike taking only water. In that case they will achieve neither functioning. But if they have a home and money in the bank they have the capability for both even if they choose to achieve neither.

In highly theorised capability accounts, such as that of Martha Nussbaum (Nussbaum 2000), it is typical to consider capabilities one by one, and to match individual capabilities against its related functioning. This then generates the question of whether someone lacks a functioning because they lack the capability, or because, while having the capability they have chosen not to exercise it. For example, arguably someone who lacks physical health purely because of a skiing accident would normally be said to have had the capability to achieve physical health, simply by not going skiing. In this case, then, they have the capability for physical 
health, but not the functioning, whereas someone born with a serious, chronic, untreatable condition will lack the capability as well as the functioning.

In Sen's initial presentation, however, capabilities were not automatically matched against functionings in this one-to-one way. This is easiest to demonstrate with an example. Consider again the functionings of a bed for a night and a nutritious meal, and imagine someone who has the money for one but not both. If they have the meal they cannot afford a bed, and if they choose a bed they cannot afford the meal. There is a sense in which they have the capability for both, but also a sense in which this is a very misleading thing to say. Hence it is more accurate to say that they have the choice between two (or perhaps three) functioning sets:

1. Bed and no meal.

2. Meal and no bed.

3. Neither meal or bed.

For Sen, to simplify, this "set of sets of functionings", which is to say the set comprised of 1, 2, and 3 (each a functioning set) is the individual's capability set, a notion that generalizes to much more complex cases, where a capability set will be very much larger. Your capability set is the set of possible functionings you can achieve. For the person in our simple example, naturally their capability set does not include other sets of possible functionings, such as the more desirable:

\section{Bed and meal.}

This simple model invites expansion in a number of ways, and here I will consider four, which I will list first and then develop in more detail. First, most obviously, from the point of view of understanding poverty, we are interested in many more functionings than the two in this model. As I discussed in the last section, a poverty line will generally be defined in terms of what is needed to achieve a wider set of functionings. Second, we are generally interested not only in what people can do now, but how well they can be assured of sustaining their functionings over time. Third, there are likely to be interaction effects between different functionings. Fourth, and to develop a point already mentioned, capabilities cannot be identified with financial resources alone. All of these considerably complicate the picture but at the same time add important detail.

I will take these expansions in reverse order, starting with the point that financial resources are not the sole determinant of a person's capability set. In other work I have suggested that there are at least three different types of inputs that help determine an individual's opportunities, and hence their capability set (Wolff 2002; Wolff and de-Shalit 2007). I have divided these into: personal resources, external resources and external structures. First, personal resources include strengths and talents, and encompass what Rawls refers to as "natural assets" (Rawls 1999) and Dworkin "internal resources" (Dworkin 1981). Second, the term "external resources" echoes Dworkin's use in that it includes wealth and income, but I would also add that a supportive social network can also be a hugely important external resource. External structures include legal, cultural, material and environmental factors that constitute the "rules of the game". A law prohibiting women or members of certain races from 
some professions; a golf-club that will not consider applications from outside an elite social or racial group; or a material environment that requires even office workers to be able to climb stairs, will all exert their effects in favouring some groups of people over others, either independently of, or in combination with, their internal and external resource holdings. Internal resources, external resources and external structures interact to determine each individual's opportunities. Hence, we can see that a concentration on poverty takes into account only one type of external resources-financial-ignoring all others, except those that it attempts to convert into a financial equivalent. This is why, as noted above, Richard Hull prefers to talk about deprivation rather than poverty (Hull 2007), and why others have made a distinction between living in poverty, which is related to having a low level of financial resources, and living an impoverished life, which is related to having a poor capability set. ${ }^{2}$ Often the two will go together, but not always. But in sum, we should accept that an individual's capability set-their ability to achieve different sets of functionings - will be determined by a wide range of factors which can be broadly characterized as internal resources, external resources and external structures, in interaction. We can see, therefore, that in order to consider how to boost an individual's capability set it would be wrong to concentrate on financial resource alone. This is one sense in which we need to move beyond poverty as conventionally understood.

I introduced above four expansions of the simple model of poverty. Continuing to work in reverse order, the third was the point that there are likely to be interaction effects between the different functionings. Avner de-Shalit and I refer to these as "fertile functionings" and "corrosive disadvantages" (Wolff and de-Shalit 2007). A fertile functioning is one that is likely to bring benefits to other functionings. It is plausible that a strong social network is a valuable functioning in its own right, but it is also a means to other functionings, in that, for example, it might help you become aware of job opportunities and support you through the application process. A supportive social network can help you achieve mental and physical health, improve knowledge and understanding, and help in other ways. Hence it appears to be a fertile functioning. By contrast, drug addiction is both a disadvantage in itself and likely to lead to such things as job loss, loss of home and relationship difficulties. Therefore, it is a corrosive disadvantage. These mechanisms suggest that capability sets will be dynamic in the sense that once achieved they will change over time as a result of their own logic. At any point, therefore, in attempting to represent capability sets it is possible to give only a snapshot.

The next expansion also considers the dynamic aspect of capability sets, distinguishing between achieving a functioning at a moment and sustaining it over time. Here, also, a probabilistic element is likely to enter. It will be rare that a capability can be guaranteed over time, but it will be possible to estimate probabilities and hence estimate relative security. Such an analysis is now standard in poverty analysis, by means of concepts such as "food insecurity" (Dowler and O'Connor 2012).

\footnotetext{
${ }^{2}$ I owe this distinction to Fran Bennett.
} 
Finally, in reverse order, there was the question of what level and types of capability and functioning are sufficient to exit or overcome poverty: how, in other words, to draw the poverty line. I want to take this in two stages. First, I want to show how Sen's approach to the relation between capability and functioning helps us model ideas of absolute, relative and secondary poverty; and second, I want to return to the question of how to understand the idea of a poverty line.

To take the first step, we need initially to group different functionings into types. In the simple model introduced earlier I used "a bed for the night" and "a nutritious meal". Roughly these functionings are members of a group related to day-to-day survival, including avoiding debilitating severe hunger, as we saw emphasized by Maslow. We can call them "survival functionings". Yet these alone will not guarantee what Rowntree called "physical efficiency", for they ignore longer term factors. For example, they will not include all needed vitamins and minerals, the necessary variety of clothing for different seasons, aspects of hygiene, and so on. The second category, then, we can call "physical efficiency functionings", which will overlap with, but go well beyond survival functionings. A third category will be those things needed to have an acceptable family and social life: such as the ability to buy birthday presents, to celebrate religious holidays, to have the occasional evening out, and an annual holiday away from home. Finally, there are goods that provide "status functionings", the lack of which marks one out as poor. Many of the earlier goods will fall into this category too, but there are some that are closer to "pure status goods". Adam Smith's famous examples of leather shoes and a linen shirt fall into this category, as does the right brand of trainers or other leisure clothes for children, but also, much more deeply, celebrating marriage and burying one's dead in the right way (these will have a social dimension as well as a status element.) To summarize, let us distinguish between survival, physical efficiency, social, and status goods, in that these goods will facilitate functionings of these different types. As noted above, for many people social and/or status goods are necessary to live a truly human life, rather than one lived on a "fodder" basis.

Those who do not have the capability to achieve even their survival needs are in imminent danger of death and hence are in the most extreme poverty possible. Their set of sets of functionings is extremely meagre - there is very little they can do to meet their needs - and in the worst case virtually empty. Those who can survive but not meet their physical efficiency needs are in absolute poverty, as commonly understood, or primary poverty, in Rowntree's terms. Their set of sets of functionings does not include any acceptable set. ${ }^{3}$ Those who can achieve physical efficiency yet not social and status functionings do manage to overcome absolute and primary poverty, but will suffer from either relative or secondary poverty, depending on their choices. To see this, note that we are describing someone who faces, schematically, the choice between two sets of functionings:

\footnotetext{
${ }^{3}$ I have ignored for the purposes of this discussion those who enhance their capability set by illegal activity. I have discussed some examples of this elsewhere under the heading of "benefit cheats", see Wolff (2015a).
} 
1. Achieve survival, achieve physical efficiency, do not achieve social functionings, do not achieve status functionings.

2. Achieve survival, do not achieve physical efficiency, achieve some of social and/ or status functionings.

Everyone faced with the choice between these two options has, therefore, the same capability set, as a capability set is understood as a set of sets of possible functionings. Here I have set out the two main alternatives, both of which are limited. Note, though, that someone who chooses the first option has opted for relative poverty, achieving physical efficiency but not being able to gain access to those things that enable "fitting in". Someone making the second choice has opted for "secondary poverty", sacrificing some physical efficiency for the sake of achieving some aspects of a human life. Hence those in relative poverty and secondary poverty can face the same capability sets, but simply make difference choices of functionings.

We turn now to the follow-up issue. What total package of functionings is needed to avoid poverty? In rejecting mere physical efficiency as an appropriate measure of poverty, it seems important to decide how to characterize the appropriate alternative line. Rowntree used an intuitive judgement concerning the minimum elements that are likely to be needed to achieve a certain level of satisfaction with life, but said little about how it was to be justified. Earlier I suggested that these are the components that, for many people, would make it possible to live as a human being rather than merely achieve an animal level of existence, but that is less an analysis than a metaphor until we can make these ideas more concrete. I made some suggestions in an earlier section, but these fell short of a full analysis. One rich and highly developed account of what should count as a human life comes from Nussbaum's version of the capability approach (Nussbaum 2000). Nussbaum has argued that a good human life requires the achievement of a wide range of human capabilities. However, while this is a noble and very attractive aspiration, it seems a stretch to say that any life that fails to achieve all of the capabilities listed by Nussbaum at an acceptable level is one that falls below a poverty line. For arguably relatively few people achieve the threshold level of every capability she lists, and it would drain the concept of poverty of useful application if it turned out that most people in wealthy societies were in poverty, even if this is true of some, even many, societies.

An alternative approach to defining the poverty line is to use a survey methodology, such as the Breadline Britain studies, according to which you are in poverty if you lack a certain number of essential needs, such as the ability to have two meals a day, warm dry bedding, a waterproof coat, the ability to visit friends and family in hospital, and the ability to repair or replace broken appliances, and so on (Mack and Lansley 2015). Yet survey methods have their limits. It is notable, for example, that in the Breadline Britain survey primary and secondary education and health-care are not recorded as essential needs, presumably because access to them in the UK is not restricted on financial grounds. Therefore, access to health and education are of no interest in trying to distinguish between those who are in poverty and those who can avoid it. Any society will have a background of met needs that it takes for granted and does not even think of including in poverty measures. In this respect, the 
inclusion of "the ability to visit friends and family in hospital" is very striking. It would rarely occur to a middle-class reader as a basic need, as it is something they are generally able to do, or, if not, it would not be for reasons that they regard as connected to poverty. Yet it is reasonable to regard its lack as a form of deprivation, and a severe one at that if, for example, the person in hospital is one's own child. With the centralization of hospitals into city centres, the expense of transport, and the difficulty of taking time off work, it can be a significant problem for some people now, even though it rarely appears in common discourse about poverty. But examples such as this show that any poverty line will be both highly contextual and highly contested. For this reason, proxy measures, such as the commonly used "60\% of median income" have an important use as a way of cutting through detailed and tangled debate (Joseph Rowntree Foundation 2009). At the same time, they need to be treated with caution, especially when, as I will argue in the next section, thinking about social policy.

\section{Beyond Poverty}

I called this paper "Beyond Poverty" for two reasons. The first is that the reasons why people care about poverty - that there are people who fail to meet a certain level of need-is a reason to care not just about low income and lack of wealth but a whole range of issues that boost or hinder a capability set. Hence, we also need to think about internal resources, non-financial external resources, and external structures in the role of improving people's lives. We need, therefore, a wider concept, such as that of deprivation or disadvantage. ${ }^{4}$ Second, we need to look for policies that will end poverty or deprivation. And these two issues naturally interact. The cases of health care and education mentioned in the last section are interesting examples of how we take for granted that certain services can be supplied without recourse to a market. The more market-dominated a society, the more important financial resources will be, and, alongside, the more important traditional definitions of poverty in terms of income. There is also enormous variation even within a single society. In many countries city-dwellers have little need of a car, whether rich or poor, whereas those living in rural areas simply could not work or shop without one. Hence to improve the capability sets of those who struggle with transport it is possible either to boost their income in order to purchase cars or pay taxi fares, or to establish a better network of public transport, as for example, in the increasing use of cable cars in hilly regions (Težak 2016).

It is for this reason that while financial definitions of poverty in terms of a percentage of median income can be helpful for monitoring poverty in broad outlines, they are highly problematic in terms of setting priorities for public policies. For they

\footnotetext{
${ }^{4}$ As mentioned above I would refer to resist the temptation of attempting to redefine "poverty" as, first, that would cut us off from much previous research, and second, it does have its uses as a concept, to which I will return.
} 
would encourage policy makers to think in terms of financial redistribution by means of tax and transfer when it may well be that other types of solutions would be more effective in improving capability sets. In the short term, nevertheless, addressing the income of people in poverty is generally easier than introducing new modes of transport, or reforming the workplace, or changing laws or cultural understandings. For short-term change, therefore, poverty as traditionally understood is a very useful direct policy target, though even here thought is needed to understand how poverty is experienced in order to design the most effective ways of dealing with it.

While it is reasonable to assume that the problem of poverty, understood purely in financial terms, is a matter of lack of income, detailed examination shows that there are other important intensifying causes, most notably erratic cash flow. Someone who relies on a car for work and is on a low regular income can be blown off course by the cost of emergency car repairs, for example. Murdoch and Schneider show that even a mundane and routine mismatch between income and expenditure schedules can have serious consequences. For example, people on fortnightly pay cheques but monthly bills will have some months with three pay cheques but many more with only two. This can make planning difficult, as can being placed on a "zero hours" contract, or relying on commission or tips. In one unusual case, the authors report that a croupier at a casino expected to receive significantly more income from tips in odd-numbered years than even-numbers as some big-spending customers would visit only on the weekend of certain college football games which took place only every second year (Morduch and Schneider 2017, p. 26).

Recommendations from Morduch and Schneider start from the suggestion that temporary poverty is much more common than grinding poverty (Morduch and Schneider 2017, p. 152) and much could be achieved through fairly simple improvements in the regulation of work, such as the provision of more regular hours (Morduch and Schneider 2017, p. 170) and the availability of fairer financial products to encourage smoothing between income and expenditure (Morduch and Schneider 2017, p. 171). Alongside other ways of boosting the income of those who are struggling to meet their needs, poverty can be substantially reduced if there is the political will to do so.

At the same time, it is important to be aware of some possible perverse effects of policies designed to help those who are in work but on low income. Consider the policy in the UK of providing tax-funded supplements to the income of those on low pay, sometimes also known as negative income tax. While helpful in addressing low income and thereby helping some people and families out of poverty, it has been pointed out that knowledge that such schemes exist provides firms with an incentive to keep wages low. For some small companies that cannot afford an economic wage there may be a case for tax-funded subsidies, but for large, highly profitable companies, such a hidden subsidy — sometimes known as "corporate welfare" — increases inequality by channelling general tax revenue to the company shareholders who

\footnotetext{
${ }^{5}$ I thank Lucy Parker for this term and example.
} 
profit from low wages. We must keep in mind that ending poverty is only one social goal, and there are better and worse ways of doing so.

As I have suggested, income adjustment, and, perhaps, the availability of new financial products is a very helpful way of addressing poverty. ${ }^{6}$ Yet, as I have emphasized, there can be other ways of addressing deprivation or disadvantage, and in the longer-term we should look for changes that make redistribution unnecessary. ${ }^{7}$ Elsewhere I have called on the wisdom of Benjamin the Donkey in Orwell's Animal Farm to make the point: "God gave me a tail to keep off the flies, but I would sooner have had no tail and no flies" (Wolff 2002, p. 208; Orwell 1951, p. 2). Ideally, we need to look for solutions that make further intervention redundant. We need to explore all the determinants of opportunity to see where they can be most effective. And in thinking about effectiveness we need to keep in mind a wide range of capabilities or needs. In particular, those forms of social policy that avoid singling out and stigmatizing individuals have an advantage over those that risk humiliating individuals, even if both are equally effective in meeting a more confined set of basic needs (Wolff 2002; Wolff and de-Shalit 2007). Hence, for example, having a means test for free school meals, and requiring those who received them to stand in a separate line to show their voucher has a very obvious cost. Better to have free school meals for all, funded by tax on those above a certain threshold. This can be defended within the capability approach by emphasizing the very high value of the functioning of self-respect. Yet within this approach no value takes absolute priority and other cases may need to be dealt with in other ways.

\section{Conclusion}

I have assumed that there is a broad consensus that poverty is an evil that should be eradicated. I also assume that many people who hold this view implicitly rely on a very simple theory of poverty in which it is understood as the lack of financial resources to meet an austere menu of basic needs. Exploring the idea of poverty, however, leads us to a richer account of what is needed in order to lead a recognizably human life, and a more complex theory of social causation in which a number of different factors combine to render a decent life very difficult or unobtainable for some. Indeed, when we understand what it would mean to move beyond poverty in a social policy sense we need to move beyond poverty in a conceptual sense. The evil of poverty, understood as deprivation or disadvantage is unlikely to be removed purely by financial measures. Hence, we should look beyond poverty, both in policy terms and conceptual terms. Yet in thinking about shorter term objectives, poverty understood essentially in financial terms, is extremely helpful, both because of the political consensus around its mitigation, and the simplicity and clarity of policies

\footnotetext{
${ }^{6}$ For further discussion of anti-poverty policies see Wolff (2018).

${ }^{7}$ This is now sometimes called "pre-distribution" (see Hacker 2011).
} 
that can help. Yet the hard work remains of leveraging public disapproval of poverty into social policy, with much of the world currently rapidly moving in the wrong direction. ${ }^{8}$

\section{References}

Collins, Daryl, Jonathan Jonathan, Stuart Rutherford, and Orlanda Ruthven. 2009. Portfolios of the poor. Princeton: Princeton University Press.

Dowler, Elizabeth A., and Deirdre O'Connor. 2012. Rights-based approaches to addressing food poverty and food insecurity in Ireland and UK. Social Science \& Medicine 74: 44-51.

Dworkin, Ronald. 1981. What is equality? Part 2: Equality of resources. Philosophy \& Public Affairs 10: 283-345.

Hacker, Jacob. 2011. The institutional foundations of middle-class democracy. Policy Network. http://www.policy-network.net/pno_detail.aspx?ID=3998\&title=The-institutional-foundations-of-middle-class-democracy. Accessed 2 Sept 2017.

Hull, Richard. 2007. Deprivation and freedom. London: Routledge.

Jones, John. 1990. Poverty and human condition: A philosophical inquiry. Lewiston/New York: Edwin Mellen Press.

Joseph Rowntree Foundation. 2009. Reporting poverty in the UK. York: Joseph Rowntree Foundation.

Lister, Ruth. 2004. Poverty. Cambridge: Policy.

Lötter, Hennie. 2011. Poverty ethics and justice. Cardiff: University of Wales Press.

MacIntyre, Alasdair. 1999. Rational dependent animals. Chicago: Open Court.

Mack, Joanna, and Stewart Lansley. 2015. Breadline Britain. London: Oneworld.

Maslow, Abraham H. 1943. A theory of human motivation. Psychological Review 50: 370-396.

Morduch, Jonathan, and Rachel Schneider. 2017. The financial diaries: How American families cope in a world of uncertainty. Princeton: Princeton University Press.

Narayan, Deepa, Raj Patel, Kai Schafft, Anne Rademacher, and Sarah Koch-Schulte. 2000. Voices of the poor: Vol. 1, Can anyone hear us? New York: Oxford University Press for the World Bank.

Noddings, Nel. 1984. Caring. Berkeley: University of California Press.

Nussbaum, Martha. 2000. Women and human development. Cambridge: Cambridge University Press.

Orwell, George. 1951. Animal farm. London: Penguin.

Rawls, John. 1999. A theory of justice. Rev. ed. Oxford: Oxford University Press.

Ridge, Tess. 2002. Childhood poverty and social exclusion: From a child's perspective. Bristol: Policy Press.

Rowntree, Benjamin S. 1901. Poverty: A study of town life. London: Macmillan. . 1937. The human needs of labour. Rev. ed. London: Longmans Green \& Co.

Scanlon, T.M. 1975. Preference and urgency. Journal of Philosophy 72: 655-699.

Sen, Amartya. 1980. Equality of what? In Tanner lectures on human values, ed. Sterling M. McMurrin, vol. 1, 195-220. Salt Lake City: University of Utah Press.

1983. Poor, relatively speaking. Oxford Economic Papers 35: 153-169. 1999. Development as freedom. Oxford: Clarendon Press.

Smith, Adam. 1976. In An inquiry into the nature and causes of the wealth of nations, ed. Roy H. Campbell and Andrew S. Skinner. Oxford: Clarendon Press.

${ }^{8}$ I am very grateful to the editors of this volume for their suggestions which have led to many improvements. 
Težak, Sergej. 2016. Increasing the capacities of cable cars for use in public transport. Journal of Public Transportation 19: 1-16.

Townsend, Peter. 1979. Poverty in the United Kingdom: A survey of household resources and standards of living. Harmondsworth: Penguin Books.

VeitWilson, John H. 1986. Paradigms of poverty: A rehabilitation of B.S. Rowntree. Journal of Social Policy 15: 69-99.

Walker, Robert. 2014. The shame of poverty. Oxford: Oxford University Press.

Wolff, Jonathan. 2002. Addressing disadvantage and the human good. Journal of Applied Philosophy 19: 207-218.

2015a. Social Equality and Social Inequality. In Social equality: On what it means to be equals, ed. Carina Fourie, Fabian Schuppert, and Ivo Wallimann-Helmer, 209-225. Oxford: Oxford University Press.

2015b. Social equality, relative poverty and marginalised groups. In The equal society, ed. George Hull Maryland, 21-42. Lanham/Boulder/New York/London: Lexington Books.

2017. Forms of differential social inclusion. Social Philosophy and Policy 34: 164-185.

2018. The ethics of anti-poverty policies. In The Routledge handbook of ethics and public policy, ed. Annabelle Lever and Andrei Poama, 344-355. London: Routledge.

Wolff, Jonathan, and Avner de-Shalit. 2007. Disadvantage. Oxford: Oxford University Press.

Wolff, Jonathan, Edward Lamb, and Eliana Zur-Szpiro. 2015. Poverty: A philosophical review. York: Joseph Rowntree Foundation.

Open Access This chapter is licensed under the terms of the Creative Commons Attribution 4.0 International License (http://creativecommons.org/licenses/by/4.0/), which permits use, sharing, adaptation, distribution and reproduction in any medium or format, as long as you give appropriate credit to the original author(s) and the source, provide a link to the Creative Commons licence and indicate if changes were made.

The images or other third party material in this chapter are included in the chapter's Creative Commons licence, unless indicated otherwise in a credit line to the material. If material is not included in the chapter's Creative Commons licence and your intended use is not permitted by statutory regulation or exceeds the permitted use, you will need to obtain permission directly from the copyright holder.

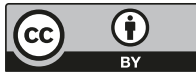

